\title{
Climatología de células convectivas con efectos severos asociados en el noreste peninsular
}

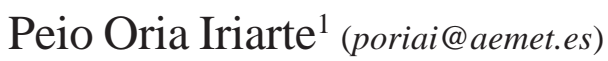

${ }^{1}$ AEMET / Delegación Territorial en Navarra

\begin{abstract}
RESUMEN
Los fenómenos meteorológicos adversos asociados a la convección severa son frecuentes durante la época cálida del año en todo el cuadrante nororiental de la península ibérica. En consecuencia, se producen tormentas acompañadas de lluvias torrenciales, elevado número de descargas eléctricas, granizadas, fuertes rachas de viento e incluso tornados de cierta magnitud.

El campo de reflectividad radar en dos dimensiones es una de las herramientas más útiles para los predictores de cara a realizar la vigilancia y seguimiento de células convectivas. Haciendo uso de mapas de reflectividad del radar de Zaragoza en modo PPI se construye una «climatología de reflectividad 2D» entre los meses de abril y octubre de los años que van de 2008 a 2017. Se han analizado más de 300000 imágenes radar con periodicidad diezminutal, discriminando aquellas que contienen estructuras convectivas cuya reflectividad radar presenta probabilidad de ocasionar efectos severos en superficie. De los atributos como el centroide de las estructuras convectivas extraídas de las imágenes de radar se obtienen mapas de reflectividad que sirven como aproximación a una climatología de células convectivas con probable severidad asociada.
\end{abstract}

PALABRAS CLAVE: convección severa; reflectividad radar; fenómenos meteorológicos adversos; climatología.

\section{INTRODUCCIÓN}

El nordeste peninsular es la región con mayor actividad convectiva de toda la península ibérica. Geográficamente destaca por su cercanía al mar Mediterráneo y su compleja orografía, caracterizada por la vertebración que marca el valle del Ebro y las distintas direcciones y orientaciones que presentan las cadenas de relieve como son los subsistemas riojano, zaragozano, turolense y castellonense del sistema Ibérico, cuyo eje principal se extiende de noroeste a sureste, las comarcas montañosas prepirenaicas del Sobrarbe, la Ribagorza y el Pallars, cuyas alineaciones montañosas no poseen una dirección predefinida, la cordillera prelitoral catalana, paralela a la línea costera y, por supuesto, el eje axial de los Pirineos, en sentido oeste-este. Por otro lado, durante los meses de la primavera, el verano y el otoño es relativamente frecuente una configuración atmosférica que ejerce un forzamiento sinóptico y que contribuye al inicio de la convección en esta zona de la Península, bien sea por el paso de una vaguada atlántica o por el acercamiento de una depresión aislada en niveles altos. Además, la baja térmica peninsular suele impulsar flujos de levante canalizados por el valle del Ebro o forzados a elevarse por las montañas que distan pocas decenas de kilómetros de la costa. Es habitual que las brisas de mar, de montaña o las convergencias de viento locales den lugar al disparo de la convección (Cuevas et al., 2017).

La convección que se desarrolla en esta zona de la Península es, con relativa frecuencia, organizada y profunda con efectos severos en superficie como lluvias torrenciales, elevado número de descargas eléctricas, 
granizadas, rachas fuertes de viento e incluso tornados de cierta magnitud (QUIRANTES, 2004). Así mismo en las climatologías de rayos de la península ibérica destacan con máximos de frecuencia anual zonas del cuadrante nororiental peninsular como la sierra turolense de Gúdar y el Maestrazgo así como el Pirineo oriental (Pérez Puebla y Zancajo, 2010).

Para el seguimiento de la iniciación y del desarrollo de la convección los predictores operativos poseen distintas herramientas de trabajo como son las imágenes de satélite, la distribución de las descargas eléctricas, los datos procedentes de estaciones de observación en superficie o las cámaras web y la información disponible a tiempo real en las redes sociales. Pero el radar meteorológico constituye, sin lugar a dudas, el apoyo indispensable para la vigilancia, seguimiento y estudio de las estructuras de precipitación (HoNG y GURLEY, 2014). El radar meteorológico es un sistema de teledetección activo basado en la emisión de pulsos en forma de ondas de radio o microondas a través de una antena parabólica en una determinada dirección (SKOLNIK, 2002). Mediante los sucesivos volúmenes de exploración del haz de radiación es posible construir distintas representaciones de los parámetros radar. EL PPI (Plane Position Indicator) muestra la distribución de la reflectividad radar 2D para un ángulo de elevación constante respecto a la superficie. En el presente estudio se han empleado datos de los volúmenes de exploración haciendo uso de las elevaciones más bajas en rango largo.

La actual red de radares de AEMET consta de 15 aparatos que emiten en banda C (longitud de onda de $5 \mathrm{~cm}$ ) y utilizan procesado Doppler en todos sus modos de operación. En este trabajo se han empleado exclusivamente datos del radar de Zaragoza, ubicado a 833 metros de altitud en el monte Oscuro perteneciente al término municipal de Perdiguera y cercano a la capital aragonesa. Se ha analizado la distribución espacial y temporal de las estructuras convectivas cuya reflectividad radar presenta probabilidad de ocasionar efectos severos en superficie en el periodo comprendido entre abril de 2008 y octubre de 2017, exceptuando los meses que van desde noviembre a marzo (e incluyendo adicionalmente los meses entre abril y julio de 2018), puesto que la convección y la probabilidad de registrarse altas reflectividades son mucho menos probables durante la época fría del año en esta zona de la Península. Para ello se cuenta con un archivo histórico de más de 300000 imágenes de radar.

\section{METODOLOGÍA}

Se emplean los dos siguientes criterios para la determinación de estructuras convectivas en las imágenes radar:

1) Inicialmente se seleccionan y enumeran las células que comprenden más de 3 píxeles contiguos cuya reflectividad en modo PPI supera los $54 \mathrm{dBZ}$. Se han eliminado las células cuyos píxeles se orientan únicamente en estructuras a lo largo de una dirección radial desde el radar. Así mismo para delimitar una estructura convectiva se comprueba que el gradiente de reflectividad en su entorno es suficientemente suave. Aplicando lo anterior se eliminan la mayor parte de ecos no meteorológicos como los asociados a aves, insectos, parques eólicos o interferencias de cualquier otro origen (MARTín LEÓN, 2001).

2) Cada estructura convectiva se clasifica por sus parámetros temporales y espaciales (hora y minuto de exploración y latitud y longitud del centroide del polígono que delimita la estructura) y por la intensidad, que se obtiene sumando las reflectividades en cada uno de los píxeles contenidos en la estructura convectiva de acuerdo a la siguiente regla:

- A los píxeles cuyo valor de reflectividad PPI está comprendido entre 54 y 59 dBZ se les asigna un valor de 0,25 .

- A los píxeles cuyo valor de reflectividad PPI está comprendido entre 60 y 65 dBZ se les asigna un valor de 0,5 .

- A los píxeles cuyo valor de reflectividad PPI es mayor o igual a $66 \mathrm{dBZ}$ se les asigna un valor de 1 . 
Se obtiene de este modo un listado con las estructuras convectivas y atributos relativos a su intensidad y extensión espacial. Finalmente, una vez extraídas todas las células de las imágenes de reflectividad radar se genera una rejilla de $5 \times 5 \mathrm{~km}$ en el área escaneada por las sucesivas exploraciones (aproximadamente un círculo de $240 \mathrm{~km}$ de radio desde el emplazamiento del radar). En cada punto de rejilla se suman las intensidades totales de las células cuyos centroides son los más cercanos a ese punto. De este modo se obtiene una climatología de reflectividad 2D cuyos máximos se asocian a las zonas con mayor probabilidad de registrarse fenómenos convectivos severos en superficie.

Por último, se lleva a cabo un kriging ordinario, como método geoestadístico de interpolación que permite suavizar la variación espacial del campo de reflectividad.

Para las tareas anteriores se ha automatizado el proceso de búsqueda, extracción y tratamiento de imágenes que contienen células convectivas mediante las siguientes tareas:

- Descarga y descompresión de los archivos de imágenes de radar del portal Big Data de AEMET.

- Determinación de los contornos de las células convectivas que cumplen los criterios anteriormente citados y asignación de los parámetros espaciotemporales e intensidad mediante la librería PIL (librería de imágenes de Python).

- Asignación de las células convectivas al punto de rejilla más cercano y aplicación del kriging ordinario.

Como ejemplo se muestra en la figura 1 la imagen radar que contiene la estructura convectiva con mayor intensidad del conjunto de las 300000 imágenes analizadas. Corresponde al 5 de junio de 2009 a las 08.30 locales. Se ha delimitado la estructura convectiva y se señala su centroide. La suma de las intensidades de los píxeles contenidos en la estructura de acuerdo al criterio introducido en el punto 2) es de 144,25 y la extensión espacial de la estructura de $780 \mathrm{~km}^{2}$.

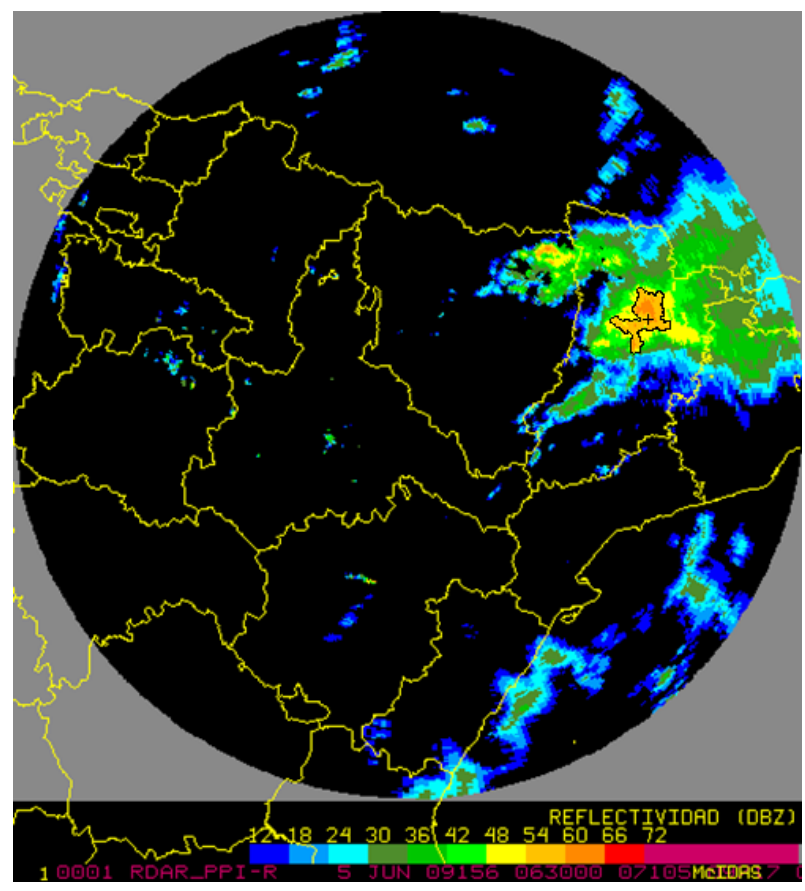

Figura 1. Estructura convectiva con intensidad y área máxima en el periodo estudiado.

Se han delimitado los píxeles contiguos con reflectividades superiores a $54 \mathrm{dBZ}$. El centroide de la estructura se ha señalado con una cruz.

\section{RESULTADOS}

Para la representación de la climatología de células convectivas se emplea un software GIS (Geographic Information System). Se obtienen resultados para el periodo completo de estudio (fig. 2) y también estratificado por trimestres (abril, mayo y junio para el periodo primaveral, junio, julio y agosto para el estival y agosto, septiembre y octubre para el otoñal). Los mapas de las climatologías trimestrales se muestran en la figura 3.

Algunas de las conclusiones principales extraíbles de la figura 2 para el periodo completo de estudio (meses comprendidos entre abril y octubre de los años 2008 y 2018 (hasta julio)) son:

- Los máximos absolutos de intensidad se dan en la Ibérica turolense y castellonense (sierras de Gúdar, Javalambre y comarcas del Maestrazgo y Puertos de Morella) y en las comarcas catalanas de Berguedà y Ripollès mientras que los máximos relativos secundarios se producen en las comarcas prepirenaicas y pirenaicas oscenses del Sobrarbe y Ribagorza, Cinco Villas de Aragón y zonas de la Ribera de Navarra e Ibérica riojana y zaragozana. 

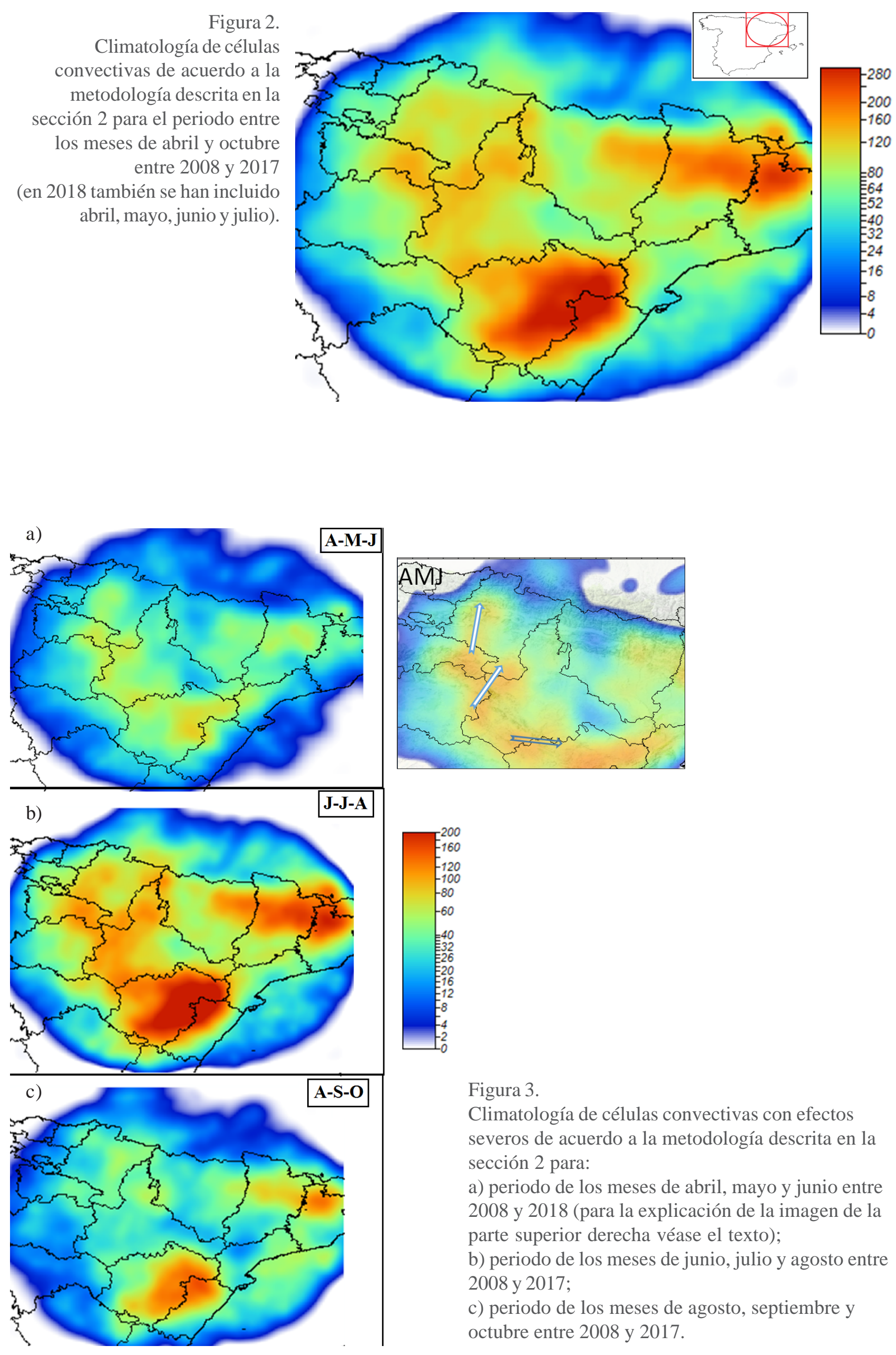

Figura 3.

Climatología de células convectivas con efectos severos de acuerdo a la metodología descrita en la sección 2 para:

a) periodo de los meses de abril, mayo y junio entre 2008 y 2018 (para la explicación de la imagen de la parte superior derecha véase el texto);

b) periodo de los meses de junio, julio y agosto entre 2008 y 2017 ;

c) periodo de los meses de agosto, septiembre y octubre entre 2008 y 2017. 
- Existe un claro bloqueo orográfico al norte de los macizos montañosos pirenaicos de más de $3000 \mathrm{~m}$ (Ordesa-Monte Perdido, Aneto-Maladetas, Vall de Boí). También se observa un bloqueo parcial por la sierra de Guara, relativamente cercana al emplazamiento del radar por el norte y cuyas cumbres principales rondan los $2000 \mathrm{~m}$ de altitud.

- Los mínimos de intensidad están situados en zonas de Castilla, valle del Ebro, interior y costa de Tarragona y Noguera leridana.

En los meses otoñales se da un máximo relativo en el mar Balear, entre el cabo de Tortosa y Barcelona, claramente asociado a la mayor actividad tormentosa debido a un mar Mediterráneo más cálido y a la formación de la baja del golfo de León (figura 3.c). También en el tercio centro-oriental de Navarra y en el sur de las Cinco Villas de Aragón aparece un máximo relativo en esta época del año.

En distintas épocas del año es frecuente encontrar que las tormentas se forman en ciertas zonas y siguen determinadas trayectorias (la asignación de centroides en imágenes radar sucesivas permite identificar el movimiento de las células). Por ejemplo, en primavera algunas zonas propicias a la formación de tormentas y las trayectorias que siguen posteriormente son (señaladas con flechas en la imagen de la parte superior derecha de la figura 3 (en la que se ha variado la escala respecto al resto de imágenes de la figura)):

- Ibérica Riojana — La Rioja Baja — Oeste/suroeste de Navarra

- Comarca del Moncayo - Ribera de Tudela

- Campo de Daroca — Valle del Jiloca

Es frecuente además que estas tormentas presenten alta probabilidad de dejar granizo en esa época del año.

Además de los mapas que muestran la distribución espacial de las estructuras convectivas se ha analizado la evolución temporal de la intensidad total de las células por años, tanto en el periodo comprendido entre abril y octubre como por los trimestres anteriormente señalados. Los resultados se muestran en la figura 4.
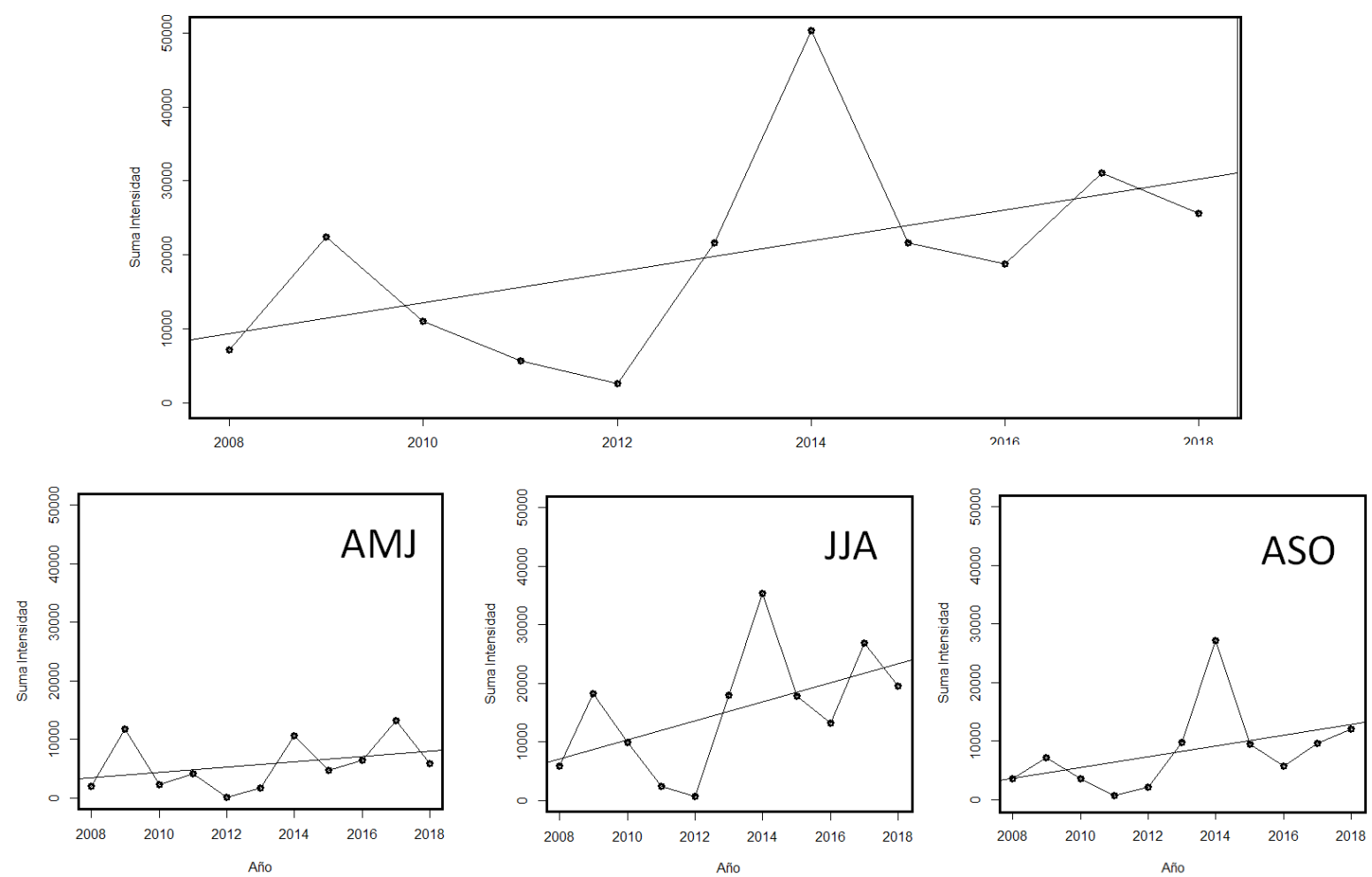

Figura 4. Evolución anual del sumatorio de la intensidad de las células convectivas seleccionadas mediante los criterios de la sección 2 para el periodo 2008-2018. Se muestra el mapa de la evolución en el periodo entre abril y octubre (arriba) así como por trimestres (abajo). Se ha añadido una recta de regresión lineal que muestra el aumento del total anual y por trimestres. 
Los años 2014 y 2017 son los años con una mayor actividad asociada a la convección severa. Es significativo que la intensidad del año con la suma más baja (2012) es un orden de magnitud menor a la suma de 2014. También destaca que un porcentaje muy elevado de la contribución a la intensidad total anual proviene de los meses de verano, como por otro lado es de esperar, dado que las condiciones propicias para la convección severa son más favorables en los meses más cálidos. En última instancia se ha efectuado el recuento para el año 2018, dadas las características del gran número de tormentas con efectos potencialmente severos y adversos acontecidas. En las gráficas de la figura 4 se han añadido las rectas de regresión lineal ajustadas a los datos. Muestran un aumento temporal de la intensidad total o climatológica de las células convectivas en el conjunto del año y también por estaciones.

\section{CONCLUSIONES}

De modo similar a las climatologías de rayos y tormentas elaboradas mediante la información de los eventos obtenidos a través de las redes de detección de descargas (Pérez Puebla y Zancajo, 2010), en esta contribución se construye una climatología de células convectivas cuyos efectos tienen alta probabilidad de ser severos. La climatología se restringe al noreste peninsular y para ello se ha hecho uso exclusivo de los datos del radar de Zaragoza en el periodo comprendido entre los meses de abril de 2008 y julio de 2018 (exceptuando los meses que van de noviembre a marzo). De hecho, los resultados son congruentes con los obtenidos en la climatología de rayos en la Península, dando muestra de que las tormentas severas llevan asociado un elevado número y frecuencia de descargas eléctricas. Algunas zonas del sistema Ibérico turolense y castellonense, así como otras del Pirineo y Prepirineo oriental son las que presentan un máximo en la distribución anual. También se observan máximos secundarios en el Mediterráneo a finales de verano y otoño, así como otros más locales en distintas épocas del año. En ocasiones los máximos se alinean en una determinada dirección constituyendo trayectorias o corredores definidos de tormentas. Es el caso de las células que se gestan en la Ibérica riojana y que, muy a menudo, se dirigen en sentido noreste hacia La Rioja Baja o la Ribera y oeste de Navarra siguiendo el flujo rector.

El hecho de poder clasificar las células convectivas por su intensidad o su distribución espaciotemporal permite ampliar el alcance de este trabajo. Por ejemplo, se pueden buscar las situaciones con una mayor severidad y tratar de ligarlas con campos meteorológicos de reanálisis u observaciones en superficie (véase la contribución «Estudio y análisis de situaciones meteorológicas asociadas a la convección severa en el noreste peninsular» en este mismo volumen). Otra posibilidad es seleccionar células convectivas semiestacionarias (extraíbles con un criterio que discrimine centroides lentamente móviles en imágenes consecutivas de radar), capaces de presentar una alta probabilidad de causar inundaciones rápidas. Para esto último se podría complementar la información obtenida del radar con otra procedente de modelos numéricos o del reanálisis tal y como sondeos, salidas de campos de viento, etc.

Por último, se ha analizado la evolución anual de la intensidad total del sumatorio de todas las células convectivas. El año 2014 presenta un máximo absoluto y el 2012 un mínimo, si bien la climatología es de solo 11 años. En cualquier caso, podría ser interesante ligar la evolución temporal del número anual de tormentas severas en el cuadrante noreste peninsular con patrones y tendencias climáticas a través de índices como el de la NAO, la circulación de las ondas de Rossby, los patrones de bloqueo, estructuras omega, etc. Otra de las conclusiones, teniendo en cuenta la información extraíble de las rectas de regresión lineal de las gráficas de la figura 4, es que los efectos severos asociados a las tormentas en el cuadrante noreste peninsular podrían estar aumentando en los últimos años. En cualquier caso, la climatología de 11 años es demasiado corta para extraer conclusiones robustas y además sería deseable examinar las tendencias con los datos obtenidos de otros radares regionales. 


\section{REFERENCIAS}

Cuevas, G., Pascual, R., Callado, A. y Compte, M., 2017. Lluvias torrenciales en el Maresme (Barcelona) el 12 de octubre de 2016. Actas de las XXXV Jornadas Científicas de la AME - 19. ${ }^{\circ}$ Encuentro Hispano-Luso de Meteorología. León, 5 al 7 de marzo de 2018. AEMET/Asociación Meteorológica Española.

Pérez Puebla, F. y Zancajo, C., 2010. Regímenes tormentosos en la Península Ibérica durante la década 2000-2009. Boletín de la Asociación Meteorológica Española (AME), 27.

Hong, Y. y Gurley, J., 2014. Radar Hydrology: Principles, Models, and Applications. 1st edition. CRC Press Taylor \& Francis Group.

Morin, E., Krajewsis , W. F., Goodrich, D. C., GaO, X. y Sorooshian, S., 2003. Estimating Rainfall Intensities from Weather Radar Data: The Scale-Dependency Problem. Journal of Hydrometeorology, 4, 782-798.

SкоLNIK, M., 2002. Introduction to Radar Systems. 3rd edition. McGraw-Hill.

QuiRANTES, J. A., 2004. Reportaje sobre los efectos del tornado asociado a la supercélula de Alcañiz (Teruel) del 23 de julio de 2003. Revista del Aficionado a la Meteorología, 17. http://www.meteored.com/ram/ numero17/tornadoalcaniz.asp.

Martín León, F. y CARRetero, O., 2001. Análisis de estructuras y células convectivas mediante datos de radar regional: aplicación YRADAR ver. 2.0. Mayo 2001, STAP, Instituto Nacional de Meteorología. 
